\title{
A pilot study of the responsiveness of the Neurogenic Bladder Symptom Score (NBSS)
}

\author{
Blayne Welk
}

Division of Urology, University of Western Ontario, London, ON, Canada

Cite as: Can Urol Assoc J 2017; Epub ahead of print. http://dx.doi.org/10.5489/cuaj.4833

\section{Published online November 1, 2017}

$* * *$

\section{Introduction}

Neurogenic bladder dysfunction is common, and has a significant impact on a person's quality of life (QOL).(1) Prior study in this area has been hampered by a limited number of validated measurement tools.(2) The Neurogenic Bladder Symptom Score (NBSS) is a relatively new 24 item questionnaire that measures bladder symptoms across 3 different domains: incontinence, storage and voiding, and consequences (with a single general urinary QOL question).(3) While validity and reliability has been assessed previously, the responsiveness (the ability of a questionnaire to detect meaningful change) of the NBSS has not been demonstrated. Our objective was to conduct a pilot study to assess the responsiveness of the NBSS.

\section{Methods}

We identified a prospective cohort of patients with neurogenic bladder who were undergoing their first intravesical injection of onabotulinum toxin A for neurogenic detrusor overactivity between December 2014-December 2016.(4) A convenience sample was used, given a lack of formal methods to determine sample size in responsiveness studies. Eligible patients were enrolled in the 2 weeks prior to intravesical onabotulinum toxin A injection, and completed a basic urologic history, the NBSS and the Qualiveen SF(5). Patients were treated as per standard practice with 100-200 IU of intravesical onabotulinum toxin A, and then returned for a follow-up visit at four to six weeks after the procedure (which was chosen to due to the rapid onset of action of onabotulinum toxin A, and to minimize the chance of other unrelated urinary changes). At this visit they completed the same two questionnaires, and a global assessment of change(6) (using a scale of -7 (a great deal worse) to +7 (a great deal better)) for each of the 3 NBSS domains and overall QOL.

Responsiveness was assessed using two methods. The first was a distributional method, which calculates responsiveness statistics based on the change in the domain score and the variability of the data. This represents the ability of the questionnaire to detect change in general (which may or may not be clinically relevant). Using the total intravesical onabotulinum toxin A patient cohort, a paired t-test (mean NBSS domain score at baseline compared to mean NBSS domain score follow-up), standardized effect size (SES), and standardized response mean (SRM) 
was calculated.(7) A statistically significant change in the NBSS domain score, or a moderate (>0.5) SES or SRM was defined a priori as significant evidence of responsiveness.(7) The second method was an anchor based approach that uses the global assessment of change score to define a clinically relevant change. Patients from the botulinum toxin cohort who reported a global assessment of change score $\geq+3$ (somewhat better) were considered improved. The mean change in the NBSS domain score was compared between improved and non-improved patients using an independent t-test and a statistically significant difference was considered evidence of responsiveness.

\section{Results}

A total of 33 consecutive patients were invited to participate; 10 declined participation, and 2 did not complete the followup visit (leaving a study size of 21 patients). Patients consisted primarily of SCI or MS patients who used intermittent catheterization (Table 1). After a median 4 (IQR 35) weeks post intravesical onabotulinum toxin A, most patients felt that their neurogenic bladder symptoms improved overall, and within each of the three domains of the NBSS. The incontinence and storage and voiding domains had large SES and SRM, and there was a significantly decreased (improved) score in each of these domains in patients who felt improved compared to patients who did not feel that their symptoms improved (Table 2). There were similar results for the single NBSS QOL question, and the NBSS total score. However, when the consequences domain was assessed, it only had a moderate SES and SRM, and there was not a significant difference in the domain score among those who improved compared to those who did not improve ( $p=0.11$ ). The NBSS results were comparable with those seen with the Qualiveen-SF: the mean score pre- to post-onabotulinum toxin A changed significantly (from 28 to 23, $\mathrm{p}=0.02$ ), and had a SES of 0.90 .

\section{Discussion}

To be responsive, a questionnaire must be reliable (meaning the patients generally answer the questions the same way if nothing has changed) and its score must change in an expected direction with changes in management or complications. This is the first assessment of the responsiveness of the NBSS, and all the domains (aside from consequences), the QOL question, and the overall score were responsive to positive change. The SES provides a measure of the magnitude of change, and is a standardized, unitless metric. All of the NBSS components (aside from the consequences domain) had a large SES ( $>0.8)$, which is consistent with good responsiveness.(8) Similarly, the SRM, which represents a signal-to-noise ratio and is impacted less by the sample size, was large $(>0.8)$ for all the NBSS components aside from the consequences domain. The magnitude of change in the scores of the 16/21 patients who reported improvement after intravesical onabotulinum toxin A was statistically significant, and as expected, the incontinence domain showed a large magnitude of change (improving by almost a third of the possible subscale range), as did the urinary QOL question (improving by over 40\% of the potential answer range). Given the content of the NBSS consequences domain (which covers subjects such as frequency of UTIs, renal stone disease, and need for bladder 
medications), it is not surprising that it was not responsive to change over a relative short time period, and that it had a lower SES (0.4).

Limitations of our study include a small sample size, however given the statistically significant results we are less concerned about type II error. Our responsiveness assessment was predicated on positive change, and we did not enough patients with a poor outcome after onabotulinum toxin to assess the ability of the NBSS to detect negative change.

\section{Conclusion}

The total NBSS score, and the subdomains of incontinence, storage and voiding and the urinary QOL question are responsive to positive clinical change and can be used to determine if a group of patients significantly improves over time or after an intervention. 


\section{References}

1. Powell CR. Not all neurogenic bladders are the same: a proposal for a new neurogenic bladder classification system. Transl Androl Urol. 2016 Feb 1;5(1):12-21.

2. Patel DP, Elliott SP, Stoffel JT, et al. Patient reported outcomes measures in neurogenic bladder and bowel: A systematic review of the current literature. Neurourol Urodyn. 2016 Jan 1;35(1):8-14.

3. Welk B, Morrow S, Madarasz W, et al. The validity and reliability of the neurogenic bladder symptom score. J Urol. 2014 Aug;192(2):452-7.

4. Karsenty G, Denys P, Amarenco G, et al. Botulinum toxin A (Botox) intradetrusor injections in adults with neurogenic detrusor overactivity/neurogenic overactive bladder: a systematic literature review. European Urology. 2008 Feb;53(2):275-87.

5. Bonniaud V, Bryant D, Parratte B, et al. Development and Validation of the Short Form of a Urinary Quality of Life Questionnaire: SF-Qualiveen. J Urol. American Urological Association; 2008 Dec 1;180(6):2592-8.

6. Beaton DE, Hogg-Johnson S, Bombardier C. Evaluating changes in health status: reliability and responsiveness of five generic health status measures in workers with musculoskeletal disorders. J Clin Epidemiol. Elsevier; 1997;50(1):79-93.

7. Terwee CB, Dekker FW, Wiersinga WM, et al. On assessing responsiveness of healthrelated quality of life instruments: guidelines for instrument evaluation. Qual Life Res. 2003 Jun;12(4):349-62.

8. Kazis LE, Anderson JJ, Meenan RF. Effect sizes for interpreting changes in health status. Med Care. 1989 Mar;27(3 Suppl):S178-89. 
Figures and Tables

\begin{tabular}{|l|c|}
\hline $\begin{array}{l}\text { Table 1. Description of demographic variables for the } \\
\text { patient cohort used in this study }\end{array}$ \\
\hline & Patient cohort (n=21) \\
\hline Age & $42($ IQR $28-57)$ \\
\hline Male & $7 / 21(33 \%)$ \\
\hline Using CIC & $15 / 21(71 \%)$ \\
\hline Etiology of neurogenic bladder \\
\hline SCI & $9 / 21(43 \%)$ \\
\hline SCI-Cervical & $2 / 9(22 \%)$ \\
\hline ASIA A & $6 / 9(67 \%)$ \\
\hline Years since SCI & $4.5(\mathrm{IQR} 1.5-5.5)$ \\
\hline MS & $8 / 21(38 \%)$ \\
\hline Relapsing/remitting & $3 / 8(38 \%)$ \\
\hline $\begin{array}{l}\text { Expanded Disability } \\
\text { Symptom Scale }\end{array}$ & $4.5(\mathrm{IQR} 2.8-6)$ \\
\hline Years since diagnosis & $19.0(\mathrm{IQR} 15-23.8)$ \\
\hline Other (congenital) & $4 / 21$ \\
\hline
\end{tabular}




\begin{tabular}{|c|c|c|c|c|c|}
\hline & \multicolumn{5}{|c|}{ NBSS domains } \\
\hline & Incontinence & $\begin{array}{l}\text { Storage } \\
\text { \& voiding }\end{array}$ & Consequences & $\begin{array}{c}\text { NBSS } \\
\text { QOL } \\
\text { question }\end{array}$ & NBSS total \\
\hline $\mathrm{N}$ & 21 & 21 & 21 & 21 & 21 \\
\hline $\begin{array}{l}\text { Mean pre-botulinum toxin } \\
\text { NBSS score (SD) }\end{array}$ & $17.0(7.0)$ & $10.9(3.8)$ & $7.0(2.8)$ & $3.7(0.6)$ & $34.9(9.8)$ \\
\hline $\begin{array}{l}\text { Mean post-botulinum toxin } \\
\text { NBSS score (SD) }\end{array}$ & $9.6(8.3)$ & $7.8(4.4)$ & $5.7(2.8)$ & $2.0(1.4)$ & $23.1(13.0)$ \\
\hline Paired t-test & $\mathrm{p}<0.01$ & $\mathrm{p}=0.02$ & $\mathrm{p}=0.16$ & $\mathrm{p}<0.01$ & $\mathrm{p}<0.01$ \\
\hline $\begin{array}{l}\text { Standardized effect size } \\
(\mathrm{SES})^{*}\end{array}$ & 1.1 & 0.8 & 0.5 & 2.5 & 1.2 \\
\hline $\begin{array}{l}\text { Standardized response mean } \\
(\mathrm{SRM})^{* *}\end{array}$ & 0.9 & 0.9 & 0.4 & 1.1 & 1.0 \\
\hline \multicolumn{6}{|l|}{$\begin{array}{l}\text { Post-botulinum toxin } \\
\text { improvement group }\end{array}$} \\
\hline $\mathrm{N}$ & 16 & 16 & 13 & 16 & 16 \\
\hline Median GAC (IQR) & $6(5-7)$ & $6(5.3-6.8)$ & $6(5-6.5)$ & $6(5.3-7)$ & $6(5-7)$ \\
\hline Mean NBSS score (SD) & $6.2(6.2)$ & $4.5(3.0)$ & $5.5(2.7)$ & $1.5(1.2)$ & $18.1(9.0)$ \\
\hline \multicolumn{6}{|l|}{$\begin{array}{l}\text { Post-botulinum toxin no } \\
\text { improvement group }\end{array}$} \\
\hline $\mathrm{N}$ & 5 & 5 & 8 & 5 & 5 \\
\hline Median GAC (IQR) & $1(-2.5$ to 1.5$)$ & $\begin{array}{c}1(-2.5 \text { to } \\
1.5)\end{array}$ & $0.5(0-1.8)$ & $\begin{array}{c}0(-0.5 \text { to } \\
1)\end{array}$ & $\begin{array}{c}1(-2.5 \text { to } \\
1.5)\end{array}$ \\
\hline Mean NBSS score (SD) & $20.4(3.6)$ & $12.0(5.3)$ & $6.0(3.0)$ & $3.8(0.4)$ & $39.2(10.5)$ \\
\hline $\begin{array}{l}\text { Mean change in score for } \\
\text { improved patients (SD) }\end{array}$ & $9.8(7.6)$ & $4.5(2.5)$ & $2.2(2.5)$ & $2.2(1.1)$ & $10.7(9.0)$ \\
\hline $\begin{array}{l}\text { Independent t-test of NBSS } \\
\text { score between improved and } \\
\text { not improved groups }\end{array}$ & $\mathrm{p}<0.01$ & $\mathrm{p}=0.02$ & $\mathrm{p}=0.11$ & $\mathrm{p}<0.01$ & $\mathrm{p}<0.01$ \\
\hline
\end{tabular}

Post-intravesical botulinum toxin, patients answered a global assessment of change question (GAC), which was used to assess whether they were improved or not. A significant paired t-test $(\mathrm{p}<0.05)$, or a SES or SRM $>0.5$ indicated responsiveness; a significant independent t-test $(p<0.05)$ between NBSS scores of those improved versus not improved indicate responsiveness. * Calculated as mean NBSS domain change score divided by the standard deviation of NBSS domain at baseline. ${ }^{* *}$ Calculated as mean of the [NBSS domain score at follow-up minus NBSS domain score at baseline] divided by the Standard deviation of NBSS domain change score. 